\title{
correspondence
}

\section{Prenatal screening: information before decision}

SIR,--Your editorial about the prenatal screening tests for spina bifida and other congenital deformities (16 February, page 595) is to be welcomed as bringing the often over-heated arguments down onto solid ground. However, your conclusion that "parents will have to realise that a decision to undergo amniocentesis should not be taken unless they are prepared to go through with an induced aboition if the indications are unfavourable" just confirms the suspicions of people like the Archbishop of Glasgow whom you rightly rebuke.

If parents are to be given the chance of making calm and rational decisions then they should have all the available evidence before they make such a decision, rather than after. By saying that because screening is expensive, no foetus which has been found to be deformed should be allowed to survive after birth, parents are being denied the choice of both knowing that a foetus is deformed and of letting it survive.

Screening, as well as allowing a mother to have an abortion, should also be able to prepare, physically and psychologically, the parents of a deformed foetus to become the parents of a living child. Foreknowledge could ease considerably the burden of a family that has agreed to include within itself a congenitally deformed child. Yours faithfully, B. Dagnall

Manchester, UK

\section{Sport throws little light on 'nature $\mathbf{v}$ nurture'}

SIR,-Professor Bondi's letter on "nature and nurture" (16 March, page 204) is too naive to let pass. He argues that because sporting success of inhabitants of the DDR has been so outstanding in recent years, as compared with the racially not dissimilar Bundesrepublik, therefore "environment must have a commanding part to play in establishing complex human physical achievements, in spite of the undoubtedly genetic determination of simple physical characteristics, such as eye colour. With such evidence plainly in front of us, what scientific sense can be assigned to attempts to establish the genetic basis of such incredibly complex attributes as "intelligence'?"

Clearly, whatever may be true of success in competitive sport has no direct bearing on intelligence; even if the argument were meaningful as far as sport is concerned, it has nothing to say about intelligence. If Bondi wishes to address himself to the problem of the genetics of intelligence, he would be well advised to look at the empirical evidence, and to acquaint himself with the theoretical justification for the methods of analysis used; only then would his criticism have any scientific value.
Argument from common-sense analogies is not generally considered to have much scientific standing.

Is anything meaningful being said even about the sporting activities of the DDR? No one has, to my knowledge, suggested that sporting success is $100 \%$ determined by heredity; just as no one has suggested anything of the kind for intelligence. We have an estimate of $20 \%$ for the environmental contribution to the variance of intelligence; we have no estimate at all for a possible environmental contribution for "success in competitive sport". If this should happen to be in the neighbourhood of $20 \%$, then it would be quite sufficient to account for the observed difference between the DDR and the Bundesrepublik. This would leave $80 \%$ of the total variance still accountable in terms of genetic causes.

I do not for a moment take these figures seriously; nothing is in fact known about sporting ability-not even whether in fact there is one, or several, or a large number of such abilities, how they are related, or indeed anything else. We do, however, know quite a lot about intelligence; perhaps Bondi would do well to acquaint himself with this large body of knowledge before taking part in a scientific controversy that passed the level of his contribution eighty years ago. Yours faithfully, H. J. EYSENCK

Institute of Psychiatry, London, UK

\section{Athletic Eskimos}

SiR,-What Professor Sir Hermann Bondi has shown (16 March, page 204) is that two genetically closely related populations may perform differently under different environmental conditions, as with the training of athletic élites in East and West Germany. But this throws little light on the nature/nurture argument, since even the most hide-bound geneticists don't claim that all variation is unaffected by the environment. Sir Hermann has not, of course, shown that inherited factors do not play an important part in athletic performance, nor even that there are no inherited differences in that respect between these two very similar populations.

It may help in illustrating the problems involved to consider the Eskimos from the point of view of sport. They are large, strong, intelligent people, well used to physical exertion, but they have not made much of a name for themselves as yet at basketball, possibly because they have unusually short legs and arms. If the same training and encouragement as is available to athletes in the DDR were to produce a world-beating Eskimo basketball team, this is the sort of evidence needed to support Sir Hermann's thesis that "it follows unambiguously that the environment must have a commanding part to play in establishing complex human achievements", regardless of genetical inheritance. There is however a problem here, which is that resources available for athletic training, as for everything else, are limited, and some future Eskimo Olympic team might decide to concentrate on other sports, long-distance canoeing perhaps, believing that prospects there were better. Sir Hermann would no doubt consider that a prejudiced attitude, not to say an unscientific one, and it certainly begs the question of the commanding part played by environment in such matters. But it does show the practical difficulties of designing experiments to produce unambiguous answers to the questions he raises, which can seldom be done by looking post hoc at particular oases.

$$
\text { Yours faithfully, }
$$

C. B. GOODHART

University Museum of Zoology, Cambridge, UK

\section{Training or talent?}

SiR,-Professor Bondi's letter (16 March, page 204) suggested that the differences between the athletic success achieved by the DDR and West Germany demonstrated "unambiguously that environment must have a commanding part to play in establishing complex physical

achievements".

Professor Bondi would, perhaps, agree that the success of the DDR in fostering athletic achievement is based on the early identification of 'talent' and the provision of every facility for the training and development of that 'talent'.

However, without the 'talent', that is the genetic component, the intensive training and development, that is the environmental component, might not produce results. In this situation how much of the success is due to the existence of talented individuals in the population and how much to training $\longrightarrow$ or is this where we came in? Yours faithfully,

Unive, sity of Leicester, UK

\section{K. E. REEve}

\section{Call for engineers}

SIR,-The government appointed Committee of Inquiry into the engineering profession, of which I am chairman, is anxious to conduct an analysis of the distribution and deployment of men and women with engineering qualifications, covering both those within engineering functions in industry and those now working in quite different areas of activity.

In this context we are particularly keen to contact people who qualified as engineers but who are now working in fields where their engineering skills are not directly relevant. May I therefore, through the columns of your paper, invite such people who are willing to complete a simple, confidential questionnaire. to send their names and addresses to the Secretariat to the Committee at Ashdown House. 123 Victoria Street, London SW1. Yours faithfully, MONTY FINNISTON 